\title{
Effects of Intimate Partner Violence on Pregnancy Outcome
}

\author{
${ }^{1}$ Kiranmai Devineni, ${ }^{2} \mathrm{~S}$ Shantha Kumari, ${ }^{3}$ Nagamani Sodumu, ${ }^{4}$ Ruchika Garg
}

\begin{abstract}
Introduction: Intimate partner violence (IPV) is a significant, yet preventable public health problem that affects millions of women regardless of age, economic status, race, religion, ethnicity, sexual orientation, or educational background. The IPV has been associated with poor pregnancy outcomes, such as anemia, still birth, abruption, fetal injury, preterm delivery, and low birth weight. With this background, we did a screening study to assess prevalence, demographic features, and maternal and neonatal outcomes.
\end{abstract}

Materials and methods: This is a prospective observational study done at the Modern Government Maternity Hospital, Osmania Medical College, Hyderabad, India. About 300 pregnant women admitted for various obstetric reasons during January 2013 and December 2013 and delivered were considered for the study. History and various aspects of domestic violence were obtained with a detailed written pro forma. Descriptive analysis was carried out to summarize relevant variables. Primary outcomes included incidence, risk factors, maternal morbidity, and fetal and neonatal outcome.

Results: About 114 women (38\%) revealed domestic violence, which is very high compared with $0.8 \%$ when there was no screening for domestic violence. A total of 186 women showed no history of violence. Demographic features and obstetric outcomes were compared. About $90 \%$ women in both groups were economically dependent. About $50 \%$ women did not have a right over their reproductive choices. About 33 women faced violence at the time of pregnancy $(28.9 \%)$. Very strong association between antenatal care booking and partner abuse was observed. About $50 \%$ had less than three visits and $64.4 \%$ of abusive partners are alcoholic. Gender bias, male child preference, unemployment, and dowry were the other common causes for abuse. Abruption was seen in $6.14 \%$ in the abuse group vs $1.79 \%$ in the control group. Preterm labor was 6.14 vs $2.15 \%$. Four women with severe acute maternal morbidity due to IPV and one case of severe sexual violence have been highlighted.

Conclusion: Domestic violence and IPV are widely prevalent, and what is visible is only the tip of the iceberg. It contributes to a

\footnotetext{
${ }^{1}$ Assistant Professor, ${ }^{2}$ Professor and Head, ${ }^{3,4}$ Associate Professor

1,3 Department of Obstetrics and Gynecology, Osmania Medical College, Hyderabad, Telangana, India

${ }^{2}$ Department of Obstetrics and Gynecology, Malla Reddy Medical College for Women, Hyderabad, Telangana, India

${ }^{4}$ Department of Obstetrics and Gynecology, Sarojini Naidu Medical College, Agra, Uttar Pradesh, India

Corresponding Author: Ruchika Garg, Associate Professor Department of Obstetrics and Gynecology, Sarojini Naidu Medical College, Agra, Uttar Pradesh, India, e-mail: ruchikagargagra@ gmail.com
}

spectrum of maternal and fetal complications. The obstetriciangynecologist has the unique opportunity to screen for domestic violence, and screening for domestic violence has to be made part of antenatal care. Linking up medical, legal, police, welfare homes, and counseling can go a long way. Millennium development goal (MDG) 3, i.e., gender parity, should be the route to achieve MDG 4 and 5 .

Keywords: Domestic violence, Intimate partner violence, Pregnancy outcome.

How to cite this article: Devineni K, Kumari SS, Sodumu N, Garg R. Effects of Intimate Partner Violence on Pregnancy Outcome. J South Asian Feder Obst Gynae 2018;10(2):142-148.

\section{Source of support: Nil}

Conflict of interest: None

Date of received: 15 March 2018

Date of acceptance: 20 April 2018

Date of publication: July 2018

\section{INTRODUCTION}

Intimate partner violence encompasses subjection of the partner to physical, psychological abuse, sexual violence, and reproductive coercion. This affects millions of women regardless of age, economic status, race, religion, ethnicity, or education and background. It was ranked fifth in terms of years of life lost owing to disability for women in the global burden of disease study 2010.

According to the World Health Organization (WHO) report dated July 2013, around 35\% of women experience violence at the hands of their partners or others. This is the first systematic study to examine global data on violence against women. In South East Asia including India, the Eastern Mediterranean, and sub-Saharan Africa, the incidence is at $38 \%$. Consequences of IPV are acute visible injuries to body parts, genitalia, abdomen, chronic headaches, depression, chronic pelvic pain, and irritable bowel syndrome, which are clinical manifestations of internalized stress and substance abuse; suicides also are common.

The IPV has been associated with poor pregnancy outcome, anemia, still birth, abruption, fetal injury, preterm delivery, and low birth weight. According to the WHO report, the chance of low birth weight is $16 \%$ more and human immunodeficiency virus (HIV) infection is 1.5 times more compared with women with no IPV. About 
$42 \%$ experience serious injuries at the hands of their partner. As many as 38\% of all homicides of women are committed by partners according to the new research. Surprisingly, pregnancy and postpartum periods are at increased physical and psychological vulnerability.

\section{MATERIALS AND METHODS}

This is a prospective observational study done at the outpatient department and labor ward of the Modern Government Maternity Hospital, Osmania Medical College, Hyderabad, India, during January 2013 and December 2013. All the pregnant women willing to be interviewed were included in the study. History and various aspects of domestic violence were obtained with a detailed written pro forma. All the pregnant women who gave the history of physical, emotional, or sexual abuse were grouped under group I, and every fourth patient with negative history was taken as control and included in group II. Informed consent was taken. A written questionnaire on all aspects of partner violence including physical, emotional, sexual coercion, and reproductive coercion along with demographic data was administered to all the women and filled while directly interviewing participants. Strict confidentiality was maintained and interviews were conducted in privacy after explaining the purpose of the study.

Physical abuse includes throwing objects, pushing, kicking, slapping, strangulating, hitting, beating, and threatening with any form of weapon or using a weapon. Psychological abuse includes harassment, verbal abuse, blaming, threats, stalking, and isolation. Sexual violence includes unwanted sexual coercion and rape. Reproductive coercion involves behavior that enables control and power in a relationship related to reproductive health, like sabotaging contraception, refusal to practice safe sex and exposing partner to sexually transmitted infections / HIV, forcing to either continue pregnancy or cause abortion, forbid or force sterilization, and control access to reproductive health services.

Pregnancy outcome was assessed in terms of induced abortion, miscarriage, still birth, live birth, antepartum hemorrhage $(\mathrm{APH})$, direct trauma, intrauterine fetal death (IUFD), preterm delivery birth weight, and severe maternal morbidity. The demographic data included age, parity, education, profession, religion, income, and alcohol abuse.

Preterm delivery was defined as a live birth delivered before 37 completed weeks of gestation, and term delivery was defined as delivery which occurred after 37 completed weeks of gestation. Low birth weight was defined as a live birth weighing $<2,500 \mathrm{gm}$. Spontaneous abortion was defined as fetal loss before 20 weeks of gestation.
Perinatal death was defined as fetal loss after 20 weeks of gestation up to neonatal death occurring in the first week after delivery.

Frequency and percentages were computed for all variables like age, parity, risk factors, education level, and various forms of violence, and maternal, fetal, and neonatal outcomes. Statistical Package for the Social Sciences was used for statistical analysis. Logistical regression analysis was performed to determine the effect of domestic violence on pregnancy outcomes. Relative risk was also calculated. Statistical significance was taken at $\mathrm{p}<0.05$.

\section{RESULTS}

The number of pregnant women interviewed were 286, out of which 110 were affected by violence, included in group I, giving incidence of violence as (38.46\%), while 176 women not affected by violence were included in group II (61.54\%).

Sociodemographic features of the women, such as age, parity, religion, income, and details of their partners were analyzed and are summarized in Table 1.

About $66.37 \%$ in group I and $73.86 \%$ in group II were between the age of 20 to 25 years. More importantly, $6.37 \%$ in group I were less than 20 years $(p=0.002)$. A considerable number of women belonged to Muslim religion $(56.4 \%)$ in group I compared with $35.2 \%$ in group II ( $\mathrm{p}=0.0002)$.

Six women were in unmarried status in group I and no one in group II ( $p=0.001)$. Working women were higher in group II (11.6 vs 4.6\%). Unemployment was $8.2 \%$ and up to $65 \%$ had income less than 5,000 rupees in group I, whereas there was neither unemployment nor low incomes in group II $(\mathrm{p}<0.0000001)$. The relative risk for IPV was 2.93 when the husband was unemployed or had income less than Rs. 2,000 per month.

Full antenatal care was seen in $68.2 \%$ in group II compared with $45.5 \%(n=50)$ in group I $(p=0.0007)$. Smoking (36.4\%) and alcohol (60.9\%) addictions were higher in group I compared with 17 and $38.6 \%$ respectively, in group II $(\mathrm{p}<0.0001)$ (Table 2$)$.

The second part of observations was on the type and spectrum of violence in group I. About $61.8 \%$ of women faced physical abuse. Reproductive coercion was seen in $22.7 \%$ of women. About 40 out of 110 women (36.4\%) faced violence during the present pregnancy (Tables 3 and 4).

The different forms of abuse are summarized in Table 4 .

\section{Maternal Mortality}

There were two maternal deaths. In the first instance, the provisional diagnosis was eclampsia and cerebrovascular 


\begin{tabular}{|c|c|c|c|c|}
\hline $\begin{array}{l}\text { Demographic } \\
\text { characteristic }\end{array}$ & Group I & Group II & $p$-value* & $\begin{array}{l}\text { Relative } \\
\text { risk }\end{array}$ \\
\hline \multicolumn{5}{|c|}{ Age } \\
\hline$<20$ & $07(6.4 \%)$ & - & $0.0005^{*}$ & 2.7 \\
\hline $20-25$ & $73(66.4 \%)$ & $130(73.9 \%)$ & $0.0004^{*}$ & 2.7 \\
\hline$>25$ & $30(27.2 \%)$ & $46(26.1 \%)$ & $0.001^{*}$ & 2.5 \\
\hline \multicolumn{5}{|l|}{ Religion } \\
\hline Hindu & $46(41.8 \%)$ & $114(64.8 \%)$ & $0.00007^{*}$ & 0.5 \\
\hline Muslim & $62(56.4 \%)$ & $62(35.2 \%)$ & $0.0002^{*}$ & 1.68 \\
\hline Others & $02(1.8 \%)$ & - & 0.07 & 2.63 \\
\hline \multicolumn{5}{|l|}{ Education } \\
\hline Illiterates & $55(50 \%)$ & $86(48.8 \%)$ & 0.4 & 1.03 \\
\hline Literates & $55(50 \%)$ & $90(51.2 \%)$ & & \\
\hline \multicolumn{5}{|l|}{$\begin{array}{l}\text { Education of } \\
\text { husband }\end{array}$} \\
\hline Illiterates & $48(43.6 \%)$ & $69(39.2 \%)$ & 0.2 & 1.1 \\
\hline Literates & $62(56.4 \%)$ & $107(60.8 \%)$ & & \\
\hline \multicolumn{5}{|c|}{ Marital status } \\
\hline Married & $104(94.5 \%)$ & $176(100 \%)$ & $0.001^{*}$ & 0.4 \\
\hline \multicolumn{5}{|l|}{ Residency } \\
\hline Urban & $80(72.8 \%)$ & $116(65.9 \%)$ & 0.1 & 1.2 \\
\hline $\begin{array}{l}\text { Rural } \\
\text { Profession }\end{array}$ & $30(27.2 \%)$ & $60(34.1 \%)$ & & \\
\hline Homemaker & $105(95.4 \%)$ & $156(88.6 \%)$ & $0.02^{*}$ & 2.01 \\
\hline $\begin{array}{l}\text { Working } \\
\text { Income }\end{array}$ & $05(4.6 \%)$ & $20(11.4 \%)$ & & \\
\hline $0-2,000$ & $19(17.2 \%)$ & - & $<0.0000001^{*}$ & 2.93 \\
\hline $2,000-5,000$ & $61(55.5 \%)$ & $90(51.2 \%)$ & 0.2 & 1.1 \\
\hline $5,000-10,000$ & $30(27.3 \%)$ & $75(42.6 \%)$ & $0.004^{*}$ & 0.6 \\
\hline$>10,000$ & - & $11(6.2 \%)$ & $0.002^{*}$ & 0 \\
\hline \multicolumn{5}{|l|}{ No of ANCs } \\
\hline 0 & $10(9 \%)$ & $09(5.1 \%)$ & 0.1 & 1.4 \\
\hline $1-3$ & $50(45.5 \%)$ & $47(26.7 \%)$ & 0.0006 & 1.6 \\
\hline$>3$ & $50(45.5 \%)$ & $120(68.2 \%)$ & 0.00007 & 0.5 \\
\hline
\end{tabular}

accident. A police complaint by parents and postmortem later revealed multiple fractures of skull due to fatal attack and violence by the husband.

A G3 P2 L2 with 28 weeks was attacked by axe on the neck, under the influence of alcohol. They had two girl children and there was history of gender bias and a preference for male child. There was fracture of two cervical vertebrae, transection of spinal cord, IUFD, and the patient was put on ventilator support. Pregnancy was terminated, but the woman expired after 2 days.

\section{Severe Acute Maternal Morbidity}

There were five cases of physical abuse leading to severe morbidity. One was severe APH in placenta previa following kicking by husband on abdomen, leading to massive obstetric hemorrhage, emergency hysterectomy, and multiple blood transfusions. Another woman was subjected to five induced abortions, physical abuse, and denial of
Table 2: Addictions

\begin{tabular}{lllllll}
\hline Addictions & Group I & $\%$ & Group II & $\%$ & p-value* & $\begin{array}{l}\text { Relative } \\
\text { risk }\end{array}$ \\
\hline Smoking & 40 & 36.4 & 30 & 17 & $0.0001^{*}$ & 1.76 \\
Alcohol & 67 & 60.9 & 68 & 38.6 & $0.0001^{*}$ & 1.74 \\
Both & 42 & 38.2 & 30 & 17 & $0.00004^{*}$ & 1.83 \\
\hline Total & 110 & & 176 & & & \\
\hline
\end{tabular}

Table 3: Type of violence in group I

\begin{tabular}{lll}
\hline Type of violence & Number & Percentage \\
\hline Physical & 68 & 61.8 \\
Emotional & 35 & 31.8 \\
Both & 4 & 3.6 \\
Sexual & 7 & 6.4 \\
Reproductive coercion & 25 & 22.7 \\
During pregnancy & 40 & 36.4 \\
\hline
\end{tabular}

Table 4: Type of physical violence

\begin{tabular}{lll}
\hline Type of violence & Number & Percentage \\
\hline Slapping & 38 & 34.54 \\
Kicking & 25 & 22.72 \\
Knife (sharp object) & 1 & 0.9 \\
Fracture & 2 & 1.8 \\
Throwing from 1st floor & 1 & 0.9 \\
Head injury & 2 & 1.8 \\
Forceful abortions & 5 & 4.5 \\
Denying food/starvation & 5 & 4.5 \\
Reproductive coercion & 25 & 22.72 \\
Sexual violence & 7 & 6.3 \\
Violence by in-laws & 10 & 9 \\
Whip & 1 & 0.9 \\
Burns & 1 & 0.9 \\
Electric shock & 1 & 0.9 \\
\hline
\end{tabular}

medical care. Gender bias was evident in this instance. She was brought in shock by her daughters to the emergency room with incomplete abortion. She was treated and tubectomy was done. She also required five packed red cell transfusions. The third woman was attacked by a knife on face and abdomen by husband, who was under the influence of alcohol. She had lacerations on face and penetrating injury to abdomen involving fundus of uterus. Emergency laparotomy revealed perforation of uterus, hemoperitoneum, and IUFD.

The fourth woman G3 P2 L2, with two previous cesarean sections, was pushed from first floor with fractures in both upper and lower limbs in a previous pregnancy. In the present pregnancy, she was abandoned in labor and collapsed in front of a hotel. She was brought to the hospital in emergency transport (108) with no attenders. Emergency lower (uterine) segment cesarean section was done and there was a scar dehiscence. 
Another woman, a G3 P2 L2 with 28 weeks, was subjected to severe sexual abuse by husband. She was hit by husband with sharp-edged footwear on genitalia for refusing sexual intercourse. She was brought to emergency room with a massive vulvar hematoma.

There were six unmarried pregnant women in group II, of which three ended in induced abortions and hemorrhage, and two women had no antenatal visits and brought with eclampsia in labor. One girl had full-term vaginal delivery, but episiotomy had to be sutured in the operating theater under anesthesia.

\section{Maternal Complications}

Among obstetric complications preeclampsia/eclampsia, hemorrhagic shock, and anemia were statistically significant $(\mathrm{p}<0.05)$. The other maternal complications are enumerated in Table 5.

\section{Perinatal Outcome}

Preterm labor was $4.5 \%(n=5)$ in group I and $2.8 \%(n=5)$ in group II. The IUFD was 9 vs 5.68\%. Low birth weight and neonatal intensive care unit (NICU) admissions were slightly higher in group II, but not statistically significant (Table 6).

\section{DISCUSSION}

Violence against women is a serious human rights violation and a major public health problem, so much so that

Table 5: Comparison of maternal morbidity between two groups

\begin{tabular}{lllll}
\hline Maternal morbidity & Group I & Group II & p-value & $\begin{array}{l}\text { Relative } \\
\text { risk }\end{array}$ \\
\hline Abortions & $10(9.1 \%)$ & $12(6.8 \%)$ & 0.2 & 1.2 \\
Abruption & $03(2.7 \%)$ & $03(1.7 \%)$ & 0.2 & 1.3 \\
IUFD & $10(9.1 \%)$ & $10(5.7 \%)$ & 0.1 & 1.33 \\
Preeclampsia and & $04(3.6 \%)$ & - & $0.01^{*}$ & 2.66 \\
eclampsia & & & & \\
Hemorrhagic & $03(2.7 \%)$ & - & $0.02^{*}$ & 2.64 \\
shock & & & & \\
Uterine perforation & $01(0.9 \%)$ & - & 0.1 & 2.61 \\
APH & $01(0.9 \%)$ & - & 0.1 & 2.61 \\
Anemia & $12(10.9 \%)$ & - & $0.000003^{*}$ & 2.8 \\
Rupture & $01(0.9 \%)$ & - & 0.1 & 2.61 \\
Fractures & $02(1.8 \%)$ & - & 0.07 & 2.63 \\
Death & $02(1.8 \%)$ & - & 0.07 & 2.63 \\
\hline
\end{tabular}

Table 6: Comparison of neonatal morbidity between two groups

\begin{tabular}{lllll}
\hline Neonatal morbidity & Group I & Group II & p-value & $\begin{array}{l}\text { Relative } \\
\text { risk }\end{array}$ \\
\hline Low birth weight & $05(4.5 \%)$ & $10(5.7 \%)$ & 0.3 & 0.8 \\
Preterm labor & $05(4.5 \%)$ & $05(2.8 \%)$ & 0.2 & 1.3 \\
NICU & $05(4.5 \%)$ & $10(5.7 \%)$ & 0.3 & 0.8 \\
\hline
\end{tabular}

it is proving a great hindrance to achieving the MDG and sustainable development goal related to maternal and child health. Violence in pregnancy by intimate partners is also widely prevalent. Sexual violence leading to unwanted pregnancy, unsafe abortions, and neglected pregnancies with no proper antenatal care contribute to a major chunk of maternal mortality and near-miss mortality, especially in countries like India. An understanding of the relationship between violence in pregnancy and adverse maternal outcome can have important clinical and public health implications for successful safe motherhood programs. ${ }^{1}$

Prevalence findings from the WHO multicountry study on women's health and domestic violence reported that physical or sexual partner violence or both varied from 15 to $71 \%$ globally. ${ }^{2}$ Data on violence against women showed the prevalence for India as $35.1 \%$. The latest National Family Health Survey 4 in the state of Telangana in India shows that $43 \%$ of women experienced spousal violence and $5.9 \%$ experienced violence during pregnancy. ${ }^{3}$ In a study in Canada (statistics Canada), ${ }^{4} 21 \%$ of women reported abuse in pregnancy. In our study, the prevalence was $38.46 \%$ comparable to global and national figures. The sexual violence in the WHO data was $10 \%$. In our study, it was $6.4 \%$. Violence during pregnancy in our study was $13.98 \%$. The data in Telangana showed $5.9 \%{ }^{3}$ It is interesting to note that when history was not taken, the prevalence of IPV was $1.8 \%$ from police cases and grievous injuries.

\section{Screening Protocol}

In our study, we used an elaborate survey with oral interview in a confidential, empathetic manner to identify victims. The pro forma used is shown in Table 7. Woman Abuse Screening Tool has been incorporated into the antenatal psychosocial health assessment form, as an evidence-based screening tool. ${ }^{5}$ Self-administered questionnaire and abuse assessment screening were used in the paper by Zareen et al. ${ }^{6}$ In the demographic data, educational level and economic status do not appear to affect the incidence of domestic violence in some studies. ${ }^{7}$ In the Canadian study, ${ }^{8}$ unmarried or single status and lesser income were found as risk factors for violence. Young maternal age is associated with abuse and also with single marital status. Low socioeconomic parity is also a consistent predictor of both abuse and pregnancy outcome. ${ }^{9-11}$ In our study, $6.37 \%$ were less than 20 years in the abuse group and none less than 20 in the nonabuse group. About $79.1 \%$ of women and $68.1 \%$ of men in group I had low education levels (<fifth standard), compared with $60.4 \%$ women and $50.6 \%$ men in group II. It was also observed that Muslim women 
Table 7: Pro forma used for screening violence during pregnancy

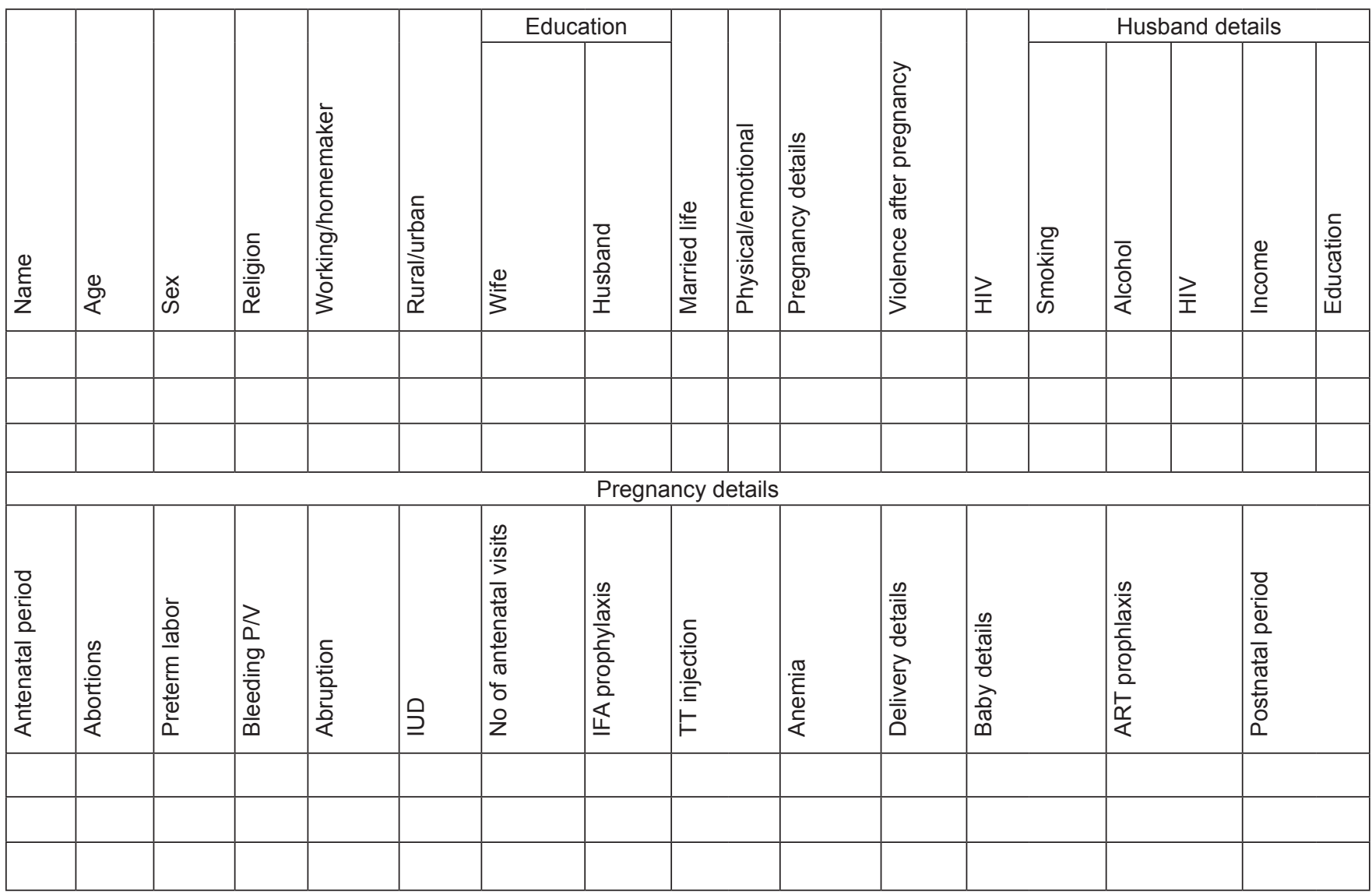

Table 8: Parity and violence

\begin{tabular}{lllll}
\hline Parity & Group I & Group II & $p$-value & Relative risk \\
\hline Primi & $37(33.6 \%)$ & $80(45.4 \%)$ & $0.02^{*}$ & 0.7 \\
P2L2 & $37(33.6 \%)$ & $50(28.4 \%)$ & 0.2 & 1.15 \\
P3L3 & $23(21 \%)$ & $46(26.2 \%)$ & 0.1 & 0.8 \\
P4L4 & $13(11.8 \%)$ & - & 0.000001 & 2.8 \\
\hline
\end{tabular}

at $56.2 \%(n=62)$ were more prone to abuse. Unmarried status, urban area, and low income were other identified factors (Tables 3, 5, and 8).

Addictions have come out as a very significant risk factor in men who abuse their partners in our study. The prevalence of addictions was overall very high in both groups, but much higher at $60.9 \%$ for group I, for alcohol and $38.6 \%$ for group II $(\mathrm{p}=0.0000001)$. In other studies too, addiction (39\%) and unemployment of husband $(7.3 \%)$ were identified as risk factors for abuse. ${ }^{6}$ In our series too, in one of the two maternal deaths and two of the near-miss mortalities, the partners were under the heavy influence of alcohol at the time of abuse.

The United Nations report in 1995 included forced pregnancy, abortion, forced sterilization, or denial of family planning as forms of violence. In our study, such forms of reproductive coercion existed in $22.7 \%$ $(\mathrm{n}=25)$.

\section{Maternal Mortality}

There exists a misconception that homicide, suicide, and accidents occur only by chance during pregnancy. ${ }^{1}$ The retrospective study in the British Journal of Obstetrics and Gynaecology found that $75 \%$ of maternal deaths found in the Department of Forensic Medicine were associated with violence. Our study unmasked two maternal deaths and five cases of severe morbidity as a direct result of IPV (\%). A community-based case-control study in India showed that deaths due to domestic violence constituted the second most common cause of death in pregnancy. ${ }^{12}$ The exact role of violence in maternal mortality can be elucidated only if history and documentation of violence are elucidated and elicited in every audit of maternal death. Antenatal care abuse during pregnancy has been associated with delayed entry into prenatal care. ${ }^{4}$ In our study also, this was observed. About $54.5 \%$ had less than three visits.

\section{Other Complications}

Fractures $(1.8 \%)$, uterine perforation $(\mathrm{n}=1)$, induced $\mathrm{APH}[0.9 \%(\mathrm{n}=1)]$, induced abortions [ $=6(5.4 \%)]$, and hemorrhagic shock $[n=3(2.7 \%)]$ were observed as a direct result of violence with serious implications to survival. The IUFD was seen in 10 (9\%) patients. In a study by Corsi 
et $\mathrm{al}^{13}{ }^{13}$ hemorrhagic shock was $11.5 \%$. Induced abortion, abruption, IUFD, and preterm premature rupture of membranes have been identified as nonfatal consequences of violence in pregnancy. ${ }^{7}$

Among obstetric complications, preeclampsia/ eclampsia (3.6\%), hemorrhagic shock $(2.7 \%)$, and anemia $(10.9 \% ; n=12)$ were statistically significant $(p<0.05)$.

A systematic review of literature ${ }^{14}$ found no consistent relationship between violence during pregnancy and adverse outcomes, but some studies have found differences in mean birth weights and low birth weight. Some studies ${ }^{14}$ felt that a direct path may involve trauma leading to preterm labor or rupture of membranes, placental abruption, or rupture uterus. Violence can lead to exacerbation of preexisting conditions that could trigger adverse outcomes. ${ }^{8,15}$ An indirect path through stress or substance abuse can lead to unwanted pregnancy, poor health care utilization, anemia, etc.

The impact of IPV on women's reproductive health and pregnancy outcomes was studied by Hall et al, ${ }^{16}$ who concluded that IPV affected woman's physical and mental health, reduced sexual autonomy, and increased risk for unintended pregnancy and multiple abortions. The IPV is a consistent and strong risk factor for unintended pregnancy, induced unsafe abortion, and severe morbidity. ${ }^{16}$

\section{Perinatal Outcome}

The literature on violence and outcome in pregnancy is not very conclusive. Most studies on newborn outcomes to date focused on low birth weight and preterm birth. ${ }^{17,18}$ In our study, preterm labor, low birth weight, and NICU admissions were only slightly higher in group II, not statistically significant.

\section{CONCLUSION}

To conclude, we observed widespread prevalence of IPV in women attending antenatal care, which was evident only by confidential and empathetic screening. There was a direct contribution to two maternal deaths and six severe acute maternal morbidity by such violence. Addiction to alcohol, low income, urban area, Muslim community, lower literacy, and gender bias emerged as risk factors in our study. Induced abortions, unwanted pregnancies, hemorrhagic shock, abruption, $\mathrm{APH}$, and IUFD were the complications that occurred due to direct effects of violence, whereas late booking and reproductive coercion can be counted as indirect effects observed due to violence on other perinatal determinants like preterm labor, preterm premature rupture of membranes, low birth weight, and intrauterine growth retardation, which could not be established. It is concluded that regular encounters with pregnant women and good screening tools to be employed universally in antenatal care provide opportunities to recognize physical and emotional components and their consequences for labor and delivery, and further offer assistance and referral as appropriate. Tying up screening and linkage to centers, such as onestop crisis center may go a long way. Further research and studies are required to help define many unresolved issues around how domestic violence affects pregnancy, labor, and delivery.

\section{LIMITATIONS}

We could not focus on psychological aspects, especially depression, suicidal tendencies, and substance abuse, in victims and the relation between HIV, acquired immunodeficiency syndrome, and domestic violence.

\section{REFERENCES}

1. Granja AC, Zacarias E, Bergström S. Violent deaths: the hidden face of maternal mortality. BJOG 2002 Jan;109(1):5-8.

2. Garcia-Moreno C, Jansen HA, Ellsberg M, Heise L, Watts CH; WHO Multi-country Study on Women's Health and Domestic Violence against Women Study Team. Prevalence of intimate partner violence: findings from the WHO multi-country study on women's health and domestic violence. Lancet 2006 Oct;368(9543):1260-1269.

3. National Family Health Survey 2015-2016 (NFHS-4): India fact sheets. Mumbai: IIPS; 2016. [cited 2017 Mar 1]. Available from: rchiips.org/NFHS/factsheet_NFHS-4.shtml\#.

4. Statistics Canada. The daily (Cat. No. 11-001E). Ottawa: Statistics Canada; 1993.

5. Reid AJ, Biringer A, Carroll JD, Midmer D, Wilson LM, Chalmers B, Stewart DE. Using the ALPHA form in practice to assess antenatal psychosocial health. Antenatal Psychosocial Health Assessment. CMAJ 1998 Sep;159(6):677-684.

6. Zareen N, Majid N, Naqvi S, Saboohi S, Fatima H. Effect of domestic violence on pregnancy outcome. J Coll Physicians Surg Pak 2009 May;19(5):291-296.

7. Widding, H.; Janson, P. Abuse of women during pregnancy. Sweden: Gothenburg University; 1999.

8. Urquia ML, O'Campo PJ, Heaman MI, Janssen PA, Thiessen KR. Experiences of violence before and during pregnancy and adverse pregnancy outcomes: an analysis of the Canadian Maternity Experiences Survey. BMC Pregnancy Childbirth 2011 Jun;11:42.

9. Taillieu TL, Brownridge DA. Violence against pregnant women: prevalence, patterns, risk factors, theories, and directions for future research. Aggress Violent Behav 2010 Jan-Feb;15(1):14-35.

10. Luo ZC, Wilkins R, Kramer MS; Fetal and Infant Health Study Group of the Canadian Perinatal Surveillance System. Disparities in pregnancy outcomes according to marital and cohabitation status. Obstet Gynecol 2004 Jun;103(6): 1300-1307. 
11. Kramer MS, Séguin L, Lydon J, Goulet L. Socio-economic disparities in pregnancy outcome: why do the poor fare so poorly? Paediatr Perinat Epidemiol 2000 Jul;14(3): 194-210.

12. Ganatra BR, Coyaji KJ, Rao VN. Too far, too little, too late: a community-based case-control study of maternal mortality in rural west Maharashtra, India. Bull World Health Organ 1998;76(6):591-598.

13. Corsi PR, Rasslan S, de Oliveira LB, Kronfly FS, Marinho VP. Trauma in pregnant women: analysis of maternal and fetal mortality. Injury 1999 May;30(4):239-243.

14. Campbell JC. Health consequences of intimate partner violence. Lancet 2002 Apr;359(9314):1331-1336.
15. Kearney MH, Munro BH, Kelly U, Hawkins JW. Health behaviors as mediators for the effect of partner abuse on infant birth weight. Nurs Res 2004 Jan-Feb;53(1):36-45.

16. Hall M, Chappell LC, Parnell BL, Seed PT, Bewley S. Associations between intimate partner violence and termination of pregnancy: a systematic review and meta-analysis. PLoS Med 2014 Jan;11(1):e1001581.

17. Altarac M, Strobino D. Abuse during pregnancy and stress because of abuse during pregnancy and birthweight. J Am Med Womens Assoc (1972) 2002 Fall;57(4):208-214.

18. Audi CA, Correa AM, Latorre Mdo R, Santiago SM. The association between domestic violence during pregnancy and low birth weight or prematurity. J Pediatr (Rio J) 2008 Jan-Feb;84(1):60-67. 